\title{
Preparing for the arrival of "pink Viagra": strengthening Canadian direct-to-consumer information regulations
}

\author{
Jean-Christophe Bélisle Pipon BSc MA, Bryn Williams-Jones PhD
}

See also www.cmaj.ca/lookup/doi/10.1503/cmaj.150363

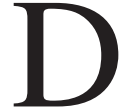
o you remember the advertisement with a cartoon elephant lying in bed between a man and a woman, implying a huge problem in the bedroom? This was the beginning of a direct-to-consumer information campaign about erectile dysfunction. Called "40over40," the campaign was sponsored by Eli Lilly, the manufacturer of Cialis (tadalafil).

The popular media focus on male sexual performance has changed following the US Food and Drug Administration's (FDA's) recent approval of flibanserin (Addyi) for the treatment of acquired, generalized hypoactive sexual desire disorder in women premenopause. ${ }^{1}$ Often called "Viagra for women" or "pink Viagra," flibanserin was twice not approved by the FDA in the past five years. ${ }^{2}$ The initial producer, Boehringer Ingelheim, transferred the rights to flibanserin to Sprout Pharmaceuticals in 2011, and rights were again recently transferred to the Canadian company Valeant Pharmaceuticals.

We can expect that an application to Health Canada will be filed soon given the recent FDA approval. If the drug is approved in Canada, Valeant will not be able to promote flibanserin using direct-to-consumer advertisements, which are permitted in the United States but prohibited under Canadian law. However, it is legal for a company to "inform" consumers about a drug through direct-to-consumer information campaigns. These campaigns, such as the one by Eli Lilly, are aimed at

... creating general disease awareness (e.g., about symptoms and associated health risks) and encouraging patients to ask their doctor about whether they might have the medical condition. ${ }^{3}$

Sprout Pharmaceuticals has cited evidence that between $7 \%$ and $33 \%$ of women have hypoactive sexual desire disorder, ${ }^{4}$ so the potential market for this drug is huge. We can thus expect flibanserin to be the subject of a direct-toconsumer information campaign in Canada, most likely with messages similar to those offered for tadalafil: that it is imperative that women be sensitized to this public health problem, one that can have a substantial impact on their quality of life - and that of their partners. Furthermore, the development of competing products by manufacturers such as Palatin Technologies shows that there is interest in producing drugs to "treat" women's libidos, a market that has been estimated to be worth US\$1.5-\$2 billion. ${ }^{5}$

What are the responsibilities of Canadian health regulators and advertising standards authorities? The 40over 40 campaign was accredited by Advertising Standards Canada, a certifying agency mandated by Health Canada to assess content and compliance of material voluntarily submitted by sponsors. However, although the campaign was judged compliant, it was rather more "promotional" than "informative" and arguably indistinguishable from prohibited advertisements. ${ }^{6}$ Flaws in existing Canadian regulations that permitted tadalafil to be marketed in this way still exist and could be exploited by Valeant.

The 40over40 campaign strongly implied that $40 \%$ of men over 40 years of age have erectile dysfunction - a rather good marketing claim, but one not well-supported by strong scientific evidence. ${ }^{3}$ In their campaign to achieve FDA approval of flibanserin, Sprout has argued that hypoactive sexual desire disorder affects as many as one in three women in the US. ${ }^{4}$ This, too, is a very convincing marketing claim, but reliable and independent scientific data show that only about 1 in 10 women experience distress as

\section{KEY POINTS}

- Direct-to-consumer advertising is not allowed in Canada, but direct-toconsumer information campaigns are legal.

- Valeant Pharmaceuticals is likely to apply for approval of its newly acquired drug, flibanserin, and to embark on such an information campaign in Canada by highlighting the "common problem" of female hypoactive sexual desire disorder.

- The federal government must ensure that Health Canada has the necessary time and resources to protect the public from so-called informational messages that are essentially another form of drug advertising. 
a result of their low desire and thus have the condition. ${ }^{7,8}$ It will be interesting to see how the quality of evidence - both with regard to the severity and incidence of the condition - is treated in any campaign in Canada.

Flibanserin is currently the only drug approved to treat hypoactive sexual desire disorder. Directto-consumer information efforts are not allowed to promote one drug over others, yet ensuring that campaigns present more than a single product would be difficult in this case. Even in the case of tadalafil, where alternative treatments existed, information was presented in such a way as to suggest that tadalafil was a "gold standard," and other nondrug alternatives were either cast in a more negative light or not mentioned at all; psychosocial interventions or counselling were not discussed, although evidence suggests that effective treatment requires a combination of approaches. ${ }^{9}$ It will also be interesting to see how Valeant deals with Advertising Standards Canada's requirement that "no element can directly or indirectly promote the sale of a drug." 10

The social context in which drug information is presented is important to consider. Sprout's preapproval campaign implied that sexism may be at play in the "undertreatment" of hypoactive sexual desire disorder, specifically pointing out that there are many drugs to treat erectile dysfunction in men but no treatment for the female equivalent., ${ }^{2,8}$ This should make alarm bells ring. Any direct-to-consumer campaign should be as neutral as possible and unbiased by a misplaced motive of responding to gender inequity. Bias is introduced if emotive campaigns that are not linked to strong evidence underpin the provision of information. What about asking the more pertinent questions of whether the existing evidence can tell us if the condition really exists or whether drugs are the only response to a "dysfunctional" level of sexual desire?

To respect the spirit of Canadian regulations, a campaign should not promote a specific treatment but only neutrally inform the public about symptoms, patient health and possible solutions. However, flaws in existing regulations mean that companies can play by these rules and still deploy campaigns that are promotional - directto-consumer advertising in all but name, as shown with tadalafil. ${ }^{6}$

Health Canada has a window of opportunity to review its current rules and procedures, recognize that the problems posed by direct-to-consumer information campaigns are essentially the same as for prohibited direct-to-consumer advertising, and move to tighten its regulations. A first step is the modernization and clarification of "The Distinction Between Advertising and Other Activities," the document that currently serves as the main reference point for regulation. The rules governing information and promotional activities must be clear to sponsors (and to the public), and supported by truly dissuasive sanctions. Health Canada must assume the responsibilities for controlling drug promotion, which are currently delegated to Advertising Standards Canada, a nongovernmental organization that relies on corporate self-regulation. Thus, the federal government must ensure that Health Canada has the necessary time and resources to protect the public from so-called informational messages that are essentially another form of drug advertising.

\section{References}

1. Flibanserin: for the treatment of hypoactive sexual desire disorder in premenopausal women. Raleigh (NC): Sprout Pharmeceuticals; 2015. Available: www.fda.gov/downloads/advisory committees/committeesmeetingmaterials/drugs/drugsafetyandrisk managementadvisorycommittee/ucm449090.pdf (accessed 2015 Oct. 23).

2. Segal JZ. The rhetoric of female sexual dysfunction: faux feminism and the FDA. CMAJ 2015;187:915-6.

3. Bélisle Pipon JC, Williams-Jones B. Drug familiarization and therapeutic misconception via direct-to-consumer information. J Bioeth Inq 2015;12:259-67.

4. FDA Advisory Committee recommends approval for Sprout Pharmaceuticals' ADDYI ${ }^{\mathrm{TM}}$ (flibanserin) to treat hypoactive sexual desire disorder in premenopausal women. Raleigh (NC) Sprout Pharmeceuticals; 2015. Available: www.prnewswire.com /news-releases/fda-advisory-committee-recommends-approval-for -sprout-pharmaceuticals-addyi-flibanserin-to-treat-hypoactive -sexual-desire-disorder-in-premenopausal-women-300094584. html (accessed 2015 Oct. 23).

5. Dearden L. "Female Viagra" could soon go on sale after approval from US drugs panel. The Independent [London] 2015 June 6. Available: www.independent.co.uk/life-style/health-and -families/health-news/female-viagra-could-soon-go-on-sale-after -approval-from-us-drugs-panel-10301956.html (accessed 2015 June 9).

6. Bélisle Pipon JC, Williams-Jones B. Regulating direct-toconsumer drug information: a case study of Eli Lilly's Canadian 40over40 Erectile Dysfunction Campaign. Healthc Policy 2015; 10:16-23.

7. Leiblum SR, Koochaki PE, Rodenberg CA, et al. Hypoactive sexual desire disorder in postmenopausal women: US results from the Women's International Study of Health and Sexuality (WISHeS). Menopause 2006;13:46-56.

8. Moynihan R. Evening the score on sex drugs: Feminist movement or marketing masquerade? BMJ 2014;349:g6246.

9. Berry MD. Historical revolutions in sex therapy: a critical examination of men's sexual dysfunctions and their treatment. $J$ Sex Marital Ther 2013;39:21-39.

10. Direct-to-consumer information guide. Toronto: Advertising Standards Canada; 2011. Available: www.adstandards.com/en/ clearance/ConsumerDrugs/DTCIGuideEN.pdf (accessed 2015 Oct. 23).

Affiliations: Bioethics Program, Department of Social and Preventive Medicine, School of Public Health, Université de Montréal; and Institut de recherche en santé publique de l'Université de Montréal, Montréal, Que.

Contributors: Jean-Christophe Bélisle Pipon wrote the first draft of the manuscript. Both of the authors contributed to the analysis and revision of the manuscript for important intellectual content, approved the final version to be published and agreed to act as guarantors of the work. 